\title{
Numerical prediction of system round-trip efficiency and feasible operating conditions of small-scale solid oxide iron-air battery
}

\section{$\operatorname{AUTHOR}(S):$}

Ohmori, Hiroko; Iwai, Hiroshi; Itakura, Kotaro; Saito, Motohiro; Yoshida, Hideo

\section{CITATION:}

Ohmori, Hiroko ... [et al]. Numerical prediction of system round-trip efficiency and feasible operating conditions of small-scale solid oxide iron-air battery. Journal of Power Sources 2016, 309: 160-168

\section{ISSUE DATE:}

2016-03-31

URL:

http://hdl.handle.net/2433/218984

\section{RIGHT:}

(c) 2016. This manuscript version is made available under the CC-BY-NC-ND 4.0 license

http://creativecommons.org/licenses/by-nc-nd/4.0/; The full-text file will be made open to the public on 31 March 2018 in accordance with publisher's 'Terms and Conditions for Self-Archiving'.; この論文は出版社版でありません。引用の際 には出版社版をご確認ざ利用ください。; This is not the published version. Please cite only the published version. 


\title{
Numerical prediction of system round-trip efficiency and feasible operating conditions of small-scale solid oxide iron-air battery
}

\author{
Hiroko Ohmori $^{\text {a, b }}$ *, Hiroshi Iwai ${ }^{\text {a }}$, Kotaro Itakura ${ }^{\text {a }}$, Motohiro Saito ${ }^{\text {a }}$, \\ and Hideo Yoshida ${ }^{\mathrm{a}}$ \\ ${ }^{a}$ Department of Aeronautics and Astronautics, Kyoto University, \\ Nishikyo-ku, Kyoto 615-8540, Japan \\ ${ }^{\mathrm{b}}$ Business Development Headquarters, Konica Minolta, Inc., \\ Osakasayama City, Osaka 569-0021, Japan
}

*Corresponding author. Tel.: +81-72-367-3543; Fax: +81-72-367-1609

E-mail address: hiroko.ohmori@konicaminolta.com 


\section{Abstract}

A simulation model of a small-scale solid oxide iron-air battery system was developed to clarify its fundamental characteristics and feasibility from the view point of energy efficiency. The energy flow in one cycle of charge/discharge operations was evaluated under a quasi-state assumption with 0-dimentional models of the system components, i.e., a solid oxide electrochemical cell, an iron (Fe) box and heat exchangers. Special care was taken when considering thermal aspects; not only a simple system but also a more complicated system with thermal recirculation by three heat exchangers was investigated. It was found that the system round-trip efficiency reaches $61 \%$ under the base conditions in this study. The results also show that several limitations exist for the operation parameters and conditions in view of practical applications. In particular, higher and lower limits exist for the fuel and air utilization factors under which the system operates effectively because of constraints such as the maximum allowable fuel-blower temperature and no heat input during the discharge operation.

\section{Key words:}

Rechargeable metal-air battery; Solid oxide electrochemical cell; Redox metal; System round-trip efficiency; Operating conditions 


\section{Introduction}

A solid oxide fuel cell has an advantage of high power generation efficiency even in systems with a relatively small capacity. Intensive research and development are underway with variety of possible applications such as portable systems [1, 2], residential cogeneration system [3-5], vehicle APUs [6] and power supply systems including hybrid system with gas turbines $[7,8]$. Recently, much attention has also been focused on its reverse reaction, namely, electrolysis [9-11]. In this reaction, steam is electrochemically decomposed into hydrogen and oxygen while consuming electrical energy. If we can effectively use this reaction, some of the input electrical energy can be stored as the chemical energy of hydrogen. The high potential of a solid oxide electrochemical cell (SOEC) as a reversible energy conversion device extended its possible applications to energy storage systems [12-24]. For example, Wendel et al. reported a thermal management of an SOEC system which produces or stores electricity by converting fuel gas $\left(\mathrm{CH}_{4}, \mathrm{H}_{2}\right.$ and $\left.\mathrm{CO}\right)$ and products gas $\left(\mathrm{CO}_{2}\right.$ and $\left.\mathrm{H}_{2} \mathrm{O}\right)$ reversibly $[12,13,20]$. Sun et al. presented a synthetic hydrocarbon fuel production using pressurized SOECs [14,22].

As one of the effective utilization methods of SOECs described above, a rechargeable battery consisting of an SOEC and a redox metal is attracting attention [25]. In this new battery, two reversible reactions simultaneously proceed at two different locations in the system; a reversible electrochemical reaction occurs at the SOEC and a reversible redox reaction occurs at the redox metal. A hydrogen/steam mixture gas plays a key role as a carrier of oxygen atoms connecting the two simultaneous reactions during both the charge and discharge operations. Iron $(\mathrm{Fe})$ is a typical choice for the redox metal and the system is often referred to as a solid oxide iron-air battery (SOIAB).

Because this battery is a new concept and still in the early stage of development, the feasibility of the concept is being intensively studied from many 
different aspects. Xu et al. [25] conducted a laboratory-scale experiment on a small tubular SOEC at $800{ }^{\circ} \mathrm{C}$. They successfully demonstrated an average round-trip efficiency of 92\%, which only considered the electrical input/output, over 20 stable charge/discharge cycles. Using an experimental setup similar to that of Xu et al., Zhao et al. [26, 27] performed cyclic durability tests. The battery was continuously cycled 100 times and a gradual decline in performance was observed. Leonide et al. [28] reported the results of a long-term operation test of a short stack at a constant temperature of $800{ }^{\circ} \mathrm{C}$. They observed a decrease in the discharge capacity but nearly $40 \%$ of the storage metal remained active even after 10,000 cycles. Although there are still problems to be solved to minimize the degradation, these experimental results are generally encouraging.

To determine in detail the phenomena occurring inside the components of batteries, numerical simulation is a powerful tool. In our previous study [29], we performed a time-dependent 1-dimentional (1-D) numerical simulation for a system consisting of a planar SOEC and iron powder packed in a rectangular region, which faced each other in an insulated box; attention was focused on the distributions of the participating gas species in the system and their effects on the performance. The time-dependent charge/discharge performance, the distributions of the concentrations and reaction rates and the effect of a change in volume of the redox metal were discussed to show the importance of effective gas diffusion in the redox metal in this system. To find the time changes of the active redox reaction area and temperature distributions, we further extended the simulation to a time-dependent 2-D simulation considering the effects of heat transfer as well as gas diffusion [30, 31]. On the other hand, Guo et al. [32] developed a 2-D numerical simulation model of a battery under a uniform temperature assumption and applied it to their laboratory-scale experiment involving a tubular packed-bed reactor combined with a planar disk electrochemical cell. The predicted time course of the terminal voltage during the discharge operation 
was in good agreement with the experimental results. More recently, Jin et al. [33] performed a time-dependent 2-D simulation taking the effects of heat transfer into account and discussed the impact of the utilization factor and the inlet temperature of the air flow.

In general, for systems developed on the basis of new concepts, numerical analysis often gives basic but essential insights into the system performances; a number of studies based on system simulations can be found not only for existing systems but also for conceptual ones, such as a large-scale solid oxide fuel cell (SOFC) and gas turbine hybrid systems, SOFC and biomass gasification systems, and direct biogas SOFC and micro gas turbine systems [7, 34]. To investigate the feasibility of the new SOIAB concept, performance analyses for various SOIAB systems are also indispensable.

In this study, we investigate the energy flow of an SOIAB system and the effects of operation parameters on the system round-trip efficiency to discuss suitable operating conditions. Because this new battery is still its early stage of the development, we assume one of the simplest configurations of the SOIAB systems to clarify the most fundamental characteristics of the system. The analyzed system is based on 0-D models of the constituent components such as the SOEC, redox metal reactor and heat exchangers introduced in our previous study [35]. We assume a home-use battery system of $5 \mathrm{kWh}$ capacity with 1-kW-class power output during a discharge operation, which corresponds to a mid-range home battery commercially available in Japan as of 2015. Calculations are conducted under a quasi-steady-state assumption and the effects of the heat exchanger effectiveness, gas utilization factors and current density on the system round-trip efficiency are examined.

\section{Numerical modeling}

\subsection{Outline of the system}


Figure 1 (a) schematically shows one of the simplest configurations of the SOIAB and its concept. The SOEC and the redox metal are the two main components of the system. In this study, we assume that the redox metal is a fine powder of iron [36-38] and we refer to the container of the Fe powder as the "Fe box" hereafter. We need to introduce two blowers in this configuration. One is for the air supply and the other is to circulate the hydrogen/steam mixture gas between the SOEC and the Fe box, which is named as "fuel-blower." The operation of the SOIAB is briefly explained below.

\section{During charge process}

The SOEC functions in an electrolysis mode. The steam is electrochemically decomposed and hydrogen is produced at the fuel electrode.

$$
\mathrm{H}_{2} \mathrm{O}(\mathrm{g})+2 \mathrm{e}^{-} \rightarrow \mathrm{H}_{2}+\mathrm{O}^{2-}
$$

$\mathrm{O}^{2-}$ migrates in the electrolyte to the air electrode, where oxygen is released to the air flow.

$$
\mathrm{O}^{2-} \rightarrow \frac{1}{2} \mathrm{O}_{2}+2 \mathrm{e}^{-}
$$

The overall reaction at the SOEC is water decomposition.

$$
\mathrm{H}_{2} \mathrm{O}(\mathrm{g}) \rightarrow \mathrm{H}_{2}+\frac{1}{2} \mathrm{O}_{2}
$$

We assume that the oxygen produced by this reaction is exhausted to the atmosphere. The hydrogen-rich mixture gas is supplied to the $\mathrm{Fe}$ box. $\mathrm{Fe}_{3} \mathrm{O}_{4}$ in the $\mathrm{Fe}$ box is reduced by hydrogen and the resultant steam-rich mixture gas is recirculated to the fuel electrode for further electrolysis by the fuel-blower.

$$
\frac{1}{4} \mathrm{Fe}_{3} \mathrm{O}_{4}+\mathrm{H}_{2} \rightarrow \frac{3}{4} \mathrm{Fe}+\mathrm{H}_{2} \mathrm{O}(\mathrm{g})
$$

Note that heat should be supplied since the electrolysis at the SOEC and the reduction of $\mathrm{Fe}_{3} \mathrm{O}_{4}$ in the $\mathrm{Fe}$ box are both endothermic reactions. If the current density is 
sufficiently high, the heat required for electrolysis can be supplied by the heat generation associated with various losses in the SOEC.

\section{During discharge process}

The SOEC functions as an SOFC. At the air electrode, oxygen in the air is electrochemically consumed as follows.

$$
\frac{1}{2} \mathrm{O}_{2}+2 \mathrm{e}^{-} \rightarrow \mathrm{O}^{2-}
$$

$\mathrm{O}^{2-}$ migrates in the electrolyte to the fuel electrode, where it reacts with hydrogen and produces steam.

$$
\mathrm{H}_{2}+\mathrm{O}^{2-} \rightarrow \mathrm{H}_{2} \mathrm{O}(\mathrm{g})+2 \mathrm{e}^{-}
$$

The overall reaction at the SOEC is

$$
\mathrm{H}_{2}+\frac{1}{2} \mathrm{O}_{2} \rightarrow \mathrm{H}_{2} \mathrm{O}(\mathrm{g})
$$

The steam-rich mixture gas is transported to the Fe box, where it oxidizes the iron, resulting in the production of hydrogen.

$$
\frac{3}{4} \mathrm{Fe}+\mathrm{H}_{2} \mathrm{O}(\mathrm{g}) \rightarrow \frac{1}{4} \mathrm{Fe}_{3} \mathrm{O}_{4}+\mathrm{H}_{2}
$$

The hydrogen-rich mixture gas is recirculated to the SOEC by the fuel-blower and consumed for further electricity generation. Note that the electrochemical reaction in the SOFC and the oxidation reaction of Fe are both exothermic.

\subsection{Assumptions and conditions}

Because the simulation method is basically the same as the one we developed in our previous study, it is only briefly explained in this section. More detailed information can be found in Ref. [35]. 
We assume that the system is in a quasi-steady state in both the charge and discharge modes. This is because our 1-D and 2-D unsteady simulations [29, 31] showed that a marked decline in performance occurred only in the last $5 \%$ of each charge/discharge process when the reactants were almost consumed. We also assume isothermal condition for the SOEC and Fe box, because our 2-D simulations predicted that maximum deviation of local temperature from the overall average temperature was approximately $30^{\circ} \mathrm{C}$ [31]. The same assumptions were employed in early literature on SOFC system analyses, e.g. Ref. [39], as well as in the recent study on SOIAB system with different system configuration [40]. Although these assumptions leave space for further development of the analysis, they have only limited effects on the fundamental characteristics of the system discussed in this paper.

Ideal thermal insulation is assumed for the entire system in this study to elucidate the most fundamental features of this new-concept system. It goes without saying that thermal insulation is critically important in a real system, particularly for the small system with high temperature components. Too thick thermal insulation layer increases not only the system size but also the cost. Effective thermal insulation will be important in order to realize the system at an allowable size and cost.

The operating temperatures of the SOEC and the Fe box are assumed to be the same for simplicity and set at $600{ }^{\circ} \mathrm{C}$. The battery capacity is $5 \mathrm{kWh}$ with 1-kW-class power output during a discharge operation. The charging time and discharging time are 10 and 5 h, respectively. The average current densities during charge/discharge processes are $50 \mathrm{~mA} / \mathrm{cm}^{2}$ and $100 \mathrm{~mA} / \mathrm{cm}^{2}$, respectively. The area-specific resistances of the SOEC associated with ohmic loss and activation overpotential are set at $A S R_{o h m}=0.10 \Omega \mathrm{cm}^{2}$ and $A S R_{a c t}=0.25 \Omega \mathrm{cm}^{2}$, respectively [41]. The concentration overpotential is neglected. The gas composition of the hydrogen/steam mixture gas at the SOEC inlet is determined assuming that the redox 
reaction reaches its equilibrium state at the exit of the Fe box. The fuel utilization factor is set at 0.5 , which is relatively low compared with that of a standard SOFC. The fuel-side blower must be operated at an elevated temperature. We assume that the maximum allowable blower temperature is $150{ }^{\circ} \mathrm{C}$. The base operating conditions in this study is summarized in Table 1 . The parameters are kept unchanged unless otherwise specified. The effects of the operation conditions are discussed in sections 3.2- 3.4.

\subsection{System round-trip efficiency}

Considering the thermal energy input to the system, we define the system round-trip efficiency, $\eta$, as

$$
\eta=\frac{P_{D}}{P_{C}+Q_{C}+Q_{D}}
$$

where $P_{C}$ and $P_{D}$ are the input and output electricity. $Q_{C}$ and $Q_{D}$ are the heat inputs to the system during the charge and discharge processes, respectively. In the calculation of the system round-trip efficiency, $Q_{C}$ and $Q_{D}$ are allowed to take non-negative values. If there is excess heat generation in the system, we assume that the excess heat is exhausted to the atmosphere and $Q_{C}$ or $Q_{D}$ is set to zero when calculating the system round-trip efficiency.

The electromotive force, $E$, is obtained from the Nernst equation as

$$
E=-\frac{\Delta G^{0}}{2 F}+\frac{R T}{2 F} \ln \left(\frac{p_{\mathrm{H}_{2}} p_{\mathrm{O}_{2}}^{1 / 2}}{p_{\mathrm{H}_{2} \mathrm{O}}}\right) .
$$

Considering the ohmic loss and activation overpotential, the terminal voltage of the SOEC in the charge/discharge process can be expressed as

$$
\begin{aligned}
& V_{C}=E+\eta_{C}=E+i_{C} \times\left(A S R_{o h m}+A S R_{a c t}\right), \\
& V_{D}=E-\eta_{D}=E-i_{D} \times\left(A S R_{o h m}+A S R_{a c t}\right)
\end{aligned}
$$


. Consequently, the input electrical energy, $P_{C}$, can be calculated as

$$
P_{C}=P_{D} \times \frac{V_{C}}{V_{D}}
$$

\subsection{Generation/absorption of thermal energy and heat transfer}

In Fig. 1, the main heat input/output during the operations are shown with the red, blue and yellow arrows. We first explain the heat input/output assuming the simple system shown in Fig. 1 (a) and then the system with thermal recirculation shown in Fig. 1 (b) is explained at the last of this section.

\section{$\underline{\text { Reaction heat }}$}

In the SOEC, heat is absorbed during the charge process via the reaction expressed by Eq. (3) and released during the discharge process by Eq. (7). The reaction heat at the SOEC during the each process can be expressed as

$$
\begin{aligned}
& Q_{C, \text { SOEC }}=n_{\mathrm{H}_{2}} \times\left(-T_{\text {SOEC }} \Delta S_{\mathrm{Eq}(3)}\right), \\
& Q_{D, \text { SOEC }}=n_{\mathrm{H}_{2}} \times\left(-T_{\text {SOEC }} \Delta S_{\mathrm{Eq}(7)}\right) .
\end{aligned}
$$

Heat is also absorbed/released at the Fe box via the reaction expressed by Eq. (4) and (8) during the charge and discharge processes, respectively. The reaction heat in the Fe box is related to the enthalpy change (reaction heat), $\Delta_{r} H$, and can be expressed as

$$
\begin{gathered}
Q_{C, F e-b o x}=n_{\mathrm{H}_{2}} \times \Delta_{r} H_{\mathrm{Eq}(4)}, \\
Q_{D, F e-b o x}=n_{\mathrm{H}_{2}} \times \Delta_{r} H_{\mathrm{Eq}(8)}=-Q_{C, F e-b o x} .
\end{gathered}
$$

\section{$\underline{\text { Losses in SOEC }}$}

Heat generation associated with the ohmic loss and activation overpotential in the SOEC is expressed in the following forms; 


$$
Q_{C, \eta}=\frac{P_{C}}{V_{C}} \times \eta_{C}, \quad Q_{D, \eta}=\frac{P_{D}}{V_{D}} \times \eta_{D}
$$

In the calculation of system round-trip efficiency, the losses in the SOEC are regarded as losses in electrical energy.

\section{Gas preheating}

To maintain a high operation temperature, the gas flows must be preheated. The maximum allowable fuel-blower temperature is $150{ }^{\circ} \mathrm{C}$ as mentioned earlier. In a simple system without thermal recirculation, the amounts of heat required to preheat the air and fuel, $Q_{\text {air }}$ and $Q_{f u e l}$, are expressed as

$$
\begin{aligned}
& Q_{\text {air }}=(c \dot{m})_{\text {air }} \times\left(T_{\text {SOEC }}-T_{\text {ambient_air }}\right) \times t, \\
& Q_{\text {fuel }}=(c \dot{m})_{\text {fuel }} \times\left(T_{\text {SOEC }}-T_{\text {fuel_blower }}\right) \times t .
\end{aligned}
$$

The heat capacities $(c \dot{m})_{\text {air }}$ and $(c \dot{m})_{\text {fuel }}$ are evaluated from the gas composition and flow rate. Gas properties are evaluated at the mean temperature.

\section{Heat inputs to system during charge and discharge processes}

The total heat input during the charge and discharge operation, $Q_{C}$ and $Q_{D}$, respectively, are obtained by summing all the terms related to the heat input/output except for the heat generated by the losses in the SOEC.

$$
\begin{aligned}
& Q_{C}=Q_{C, F e-b o x}+Q_{C, S O E C}+Q_{C, \text { air }}+Q_{C, \text { fuel }}, \\
& Q_{D}=Q_{D, F e-b o x}+Q_{D, \text { SOEC }}+Q_{D, \text { air }}+Q_{D, \text { fuel }} .
\end{aligned}
$$

Heat inputs to system with thermal recirculation

The reduction of $Q_{a i r}$ and $Q_{f u e l}$ is effective for enhancing the system round-trip efficiency. To reduce $Q_{a i r}$ and $Q_{f u e l}$, we also discuss the case with thermal recirculation using three heat exchangers (HEX1, HEX2 and HEX3) as shown in Fig. 
1 (b). The yellow arrow drawn on each heat exchanger shows the direction of heat transferred. For all the heat exchangers, the heat exchanger effectiveness was fixed at 0.85 during the charge process, unless otherwise specified.

\section{Results and discussion}

\subsection{Energy budget of fundamental system with/without thermal recirculation}

To clarify fundamental characteristics of the SOIAB, we start with a preliminary discussion of a simple system and stepwisely take more realistic factors into account. First, we focus only on the SOIAB and neglect the thermal energy required to preheat the gases. Also, we assume an ideal SOEC with no IR loss or overpotential. Under these two assumptions, $Q_{C}$ and $Q_{D}$ include only the reaction heats expressed by Eqs. (14)-(17), and thus, the system round-trip efficiency in the electrical energy budget is $100 \%\left(P_{D} / P_{C}=1.0\right)$. If we consider the thermal input, however, the round-trip efficiency of this ideal system is evaluated to be $73 \%$ from Eq. (9).

Second, when the effects of the IR loss and activation overpotential in the SOEC are considered, the input electrical energy should be increased to maintain the output electrical energy. The ratio of the electric output to the electric input, $P_{D} / P_{C}$, becomes 0.95; thus, the effects of the losses are not significant under the assumptions employed in this study. The system round-trip efficiency slightly decreases and becomes $70 \%$.

Third, we consider the thermal energy required to preheat the supply gases, Qair and $Q_{\text {fuel }}$ expressed by Eqs. (19) and (20), respectively. For the case without thermal recirculation by the heat exchangers, the starting temperatures of the air flow and fuel flow are $25{ }^{\circ} \mathrm{C}$ and $150{ }^{\circ} \mathrm{C}$, respectively. For this case, a Sankey diagram is shown in Fig. 2 (a), which shows the energy flow in the system. $C_{F e}$ (white) shown in the center corresponds to the chemical energy stored as reduced iron. The left and 
right sides correspond to the charge and discharge operations, respectively. The upper arrow (green) shows the electrical energy while the lower arrow (red) shows the thermal energy. The figures shown next to the variables are the amounts of energy in kJ. The value of $P_{D} / P_{C}$ remains at 0.95 , the same as before. As can be clearly seen from the figure, the amount of thermal energy required to preheat the gases is relatively large, and the resulting system round-trip efficiency drops to as low as $26 \%$.

Because preheating the gas requires most of the heat input we previously introduced the system with three heat exchangers in section 2.4 (Fig. 1 (b)). Table 2 summarizes the gas temperatures at various characteristic positions in the charge/discharge process. The energy flow for the present case is shown as a Sankey diagram in Fig. 2 (b). The system round-trip efficiency increases to 61\%, which shows the striking impact of thermal recirculation.

Since the thermal energy input to preheat the gases is markedly less than that shown in Fig. 2 (b), the reaction heat in the charge process becomes the main component of the heat input. To further reduce the heat input, the use of a regenerator (a storage-type heat exchanger) that recovers the heat exhausted during the discharge process is also an attractive method. Recently the simulation study of round-trip efficiency of an SOIAB system with a heat exchanger and thermal storage was published [40]. Considering the heat-loss penalty of a small-scale regenerator, however, the use of a regenerator will be more suitable for large-scale systems. The implementation of a regenerator in the system will be discussed elsewhere and is beyond the scope of this study.

For operation under the base conditions discussed above, in sections 3.2 to 3.4, we examine the effects of various parameters on the round-trip efficiency of the system to investigate its characteristics in detail. Only the parameter explicitly stated is varied while the other calculation conditions are fixed at the base conditions. 


\subsection{Effects of heat exchanger effectiveness on round-trip efficiency}

Figure 3 shows the effects of the heat exchanger effectiveness on the system round-trip efficiency. Here, the effectiveness of one heat exchanger is varied while maintaining the values for the other two heat exchangers at 0.85 . The figure shows that the effectiveness of HEX3 has a strong effect on the system round-trip efficiency. This is reasonable because the amount of heat exchanged by HEX3 is the largest among the three heat exchangers. Higher system round-trip efficiency is expected when the effectiveness of HEX3 is high. At the point marked with a square, which is “a heat-balanced point”, the input heat during the discharge process, $Q_{D}$, is equal to zero. When the effectiveness of HEX3 decreases and passes over the heat-balanced point, the slope of the round-trip efficiency becomes steeper since $Q_{D}>0$. This means that heat must be input to the system even in the discharge operation, which reduces its round-trip efficiency. The effectiveness of HEX1 also substantially affects the round-trip efficiency. When the effectiveness of HEX1 is reduced, the heat input required to preheat the fuel gas increases. This leads to a decrease in the round-trip efficiency. On the other hand, the effect of HEX2 on the system round-trip efficiency is not significant. The line comes to an end at a point marked " $x$ " in this case. This mark corresponds to the state where the temperature of the fuel mixture gas at the blower reaches the maximum allowable blower temperature $\left(150{ }^{\circ} \mathrm{C}\right)$.

\subsection{Effects of gas utilization factors on round-trip efficiency and efficient and uniform operation}

The effects of the gas utilization factors are shown in Fig. 4. The fuel and air utilization factors are set at 0.5 and 0.3 under the base conditions, respectively. The system round-trip efficiency increases with increasing air or fuel utilization factor. This is because the fuel/air flow rate decreases at a higher utilization factor, which reduces the energy required for the preheating of the gas. Because the air flow rate is 
generally higher than the fuel flow rate, the effect of the air utilization factor on the round-trip efficiency is more prominent. In particular, in the region where the air utilization factor is below the heat-balanced point, $Q_{D}>0$, the slopes become very steep and the system round-trip efficiency markedly drops. This shows the importance of operating the system under conditions where no heat input is required in the discharge operation. The maximum allowable blower temperature gives the lower limit for the fuel utilization factor and the higher limit for the air utilization factor.

In Fig. 4 (a), the calculation covers a very high fuel utilization condition. Note that the effect of fuel depletion will appear in an actual system when the fuel utilization factor is very high. Because the hydrogen molar fraction at the SOEC inlet is approximately 0.75 (the equilibrium value at $600{ }^{\circ} \mathrm{C}$ ), its value at the SOEC exit becomes less than 0.15 when the fuel utilization factor is over 0.8 in the discharge operation. To observe the effects of the gas utilization factors within the limitation of the 0-D model simulation, we calculate the EMF at the SOEC exit, $E_{\text {out, }}$ for each combination of fuel and air utilization factors, which is normalized by the EMF at the inlet, $E_{\text {in, }}$ and is shown in Fig. 4 (b) as black contour lines. A lower value of $E_{\text {out }} / E_{\text {in }}$ means a large variation of the local EMF within a single cell, which also indicates an associated non-uniformity of the local current density, temperature and overpotential distributions. In Fig. 4 (b), the combination of the fuel and air utilization factors that gives the heat-balanced condition is depicted with a blue line. To avoid the condition of $Q_{D}>0$, for which a low round-trip efficiency is expected, the system must be operated in the region to the right of the curved blue line in the figure. On the other hand, the red line in Fig. 4 (b) indicates the limit at which the fuel-blower temperature reaches its maximum allowable value of $150{ }^{\circ} \mathrm{C}$; the system must be operated in the region to the left of the red line in the figure. Consequently, the acute-angled region bounded by the blue and red lines in Fig. 4 (b) shows conditions for efficient and uniform operation under the constraints set in this study. For example, if we assume 
an allowable lower limit of $E_{\text {out }} / E_{\text {in }}$ is 0.9 , the system should be operated within the trianglular region formed by the blue line, red line and black line for $E_{\text {out }} / E_{\text {in }}=0.9$. As a result, the set of conditions for an efficient and uniform operation is obtained.

\subsection{Effects of current density on round-trip efficiency}

As shown in Fig. 5, the round-trip efficiency changes with the current density during the charge

or discharge operation. Again, note that the operation time changes with the current density according to the relationship $t_{C} i_{C}=t_{D} i_{D}$. As the current density of either operation is increased, the round-trip efficiency decreases because the electrical energy loss during the operation increases owing to higher internal losses. The marked change in the round-trip efficiency observed under the low-current-density condition in the charge operation is caused by the insufficient performance of the heat exchangers during the discharge operation. As explained in section 2.4, the heat exchangers are designed to meet the requirement for the charge operation in this study. If the current density in the charge operation is low, the required heat transfer surface area of the HEXs decreases owing to the low flow rates. The area, however, is insufficient for the discharge operation. This results in an insufficient heat recovery for the preheating of air during the discharge operation. The demand for additional heat input during the discharge operation increases, lowering the round-trip efficiency.

\section{Conclusions}

A system simulation model of an SOIAB system was developed to investigate the fundamental characteristics during the charge and discharge operations. The simulation was conducted under a quasi-state assumption with 0-D models of the system components, i.e., the SOEC, the Fe box and the heat exchangers. To clarify the 
energy balance and also improve the system round-trip efficiency, special care was taken when considering thermal aspects; not only a simple system but also a more complicated system with thermal recirculation by three heat exchangers was investigated. That is, we first defined the system round-trip efficiency in which the thermal energy as well as the electrical energy is properly taken into account. Regarding thermal recirculation, we discuss the effects of the factors practically imposed on heat exchangers, such as the temperature limit and heat exchanger effectiveness. The specific conclusions obtained in this study are summarized as follows:

(1) The theoretical round-trip efficiency of an ideal system is $73 \%$ at $600{ }^{\circ} \mathrm{C}$. Approximately $30 \%$ of the input energy is lost as reaction heat during the discharge operation. The heat generation associated with the overpotentials in the SOEC is insignificant compared with the reaction heat. When the thermal input to preheat the gases is considered, the system round-trip efficiency decreases to as low as $26 \%$. This is because the heat required to preheat the gases is much larger than the reaction heat. The system round-trip efficiency can be recovered by introducing heat exchangers to circulate thermal energy from the exhaust gases. By utilizing heat exchangers, the system round-trip efficiency recovers to $61 \%$ under the base conditions.

(2) The effects of the heat exchanger effectiveness, gas utilization and current density were examined. The effectiveness of HEX1 or HEX3 has a noticeable impact on the system round-trip efficiency, while that of HEX2 has little effect. A higher fuel/air utilization factor is generally preferred from the view point of round-trip efficiency. There is, however, an upper limit for the air utilization factor because the maximum allowable fuel-blower temperature becomes a constraint. It also gives a lower limit for fuel utilization. The operation conditions under which heat input is required even during the discharge operation were clarified for each parameter examined. The system round-trip efficiency considerably drops under these operation 
conditions. This constraint gives a lower limit for the air utilization factor. By considering the effects of the gas utilization factors, a window for operation was obtained in the air utilization and fuel utilization plane. 


\section{References}

[1] D. Pla, A. Sánchez-González, I. Garbayo, M. Salleras, A. Morata, A. Tarancón, Is it possible to design a portable power generator based on micro-solid oxide fuel cells? A finite volume analysis, J. Power Sources, 293 (2015) 264-273.

[2] M. Reissig, J. Mathé, S. Planitzer, R. Vötter, J. Rechberger, Standalone Portable SOFC Power Generator for Autonomous Operation, ECS Trans. 68(1) (2015) 143-150.

[3] R. Napoli, M. Gandiglio, A. Lanzini, M. Santarelli, Techno-economic analysis of PEMFC and SOFC micro-CHP fuel cell systems for the residential sector, Energy and Buildings, 103 (2015) 131-146.

[4] S.J.G. Cooper, G.P. Hammond, M.C. McManus, A. Ramallo-Gonzlez, J.G. Rogers, Effect of operating conditions on performance of domestic heating systems with heat pumps and fuel cell micro-cogeneration, Energy and Buildings, 70 (2014) 52-60.

[5] K.R. Ullah, R.K. Akikur, H.W. Ping, R. Saidur, S.A. Hajimolana, M.A. Hussain, An experimental investigation on a single tubular SOFC for renewable energy based cogeneration system, Energy Conversion and Management, 94 (2015) 139-149.

[6] K. Kendall, J. Newton, M. Kendall, Microtubular SOFC (mSOFC) System in Truck APU Application, ECS Trans. 68(1) (2015) 187-192.

[7] S. Wongchanapai, H. Iwai, M. Saito, H. Yoshida, Performance evaluation of a direct-biogas solid oxide fuel cell-micro gas turbine (SOFC-MGT) hybrid combined heat and power (CHP) system, J. Power Sources 223 (2013) 9-17.

[8] High Efficiency SOFC Power Cycles With Indirect Natural Gas Reforming and $\mathrm{CO}_{2}$ Capture, S. Campanari, M. Gazzani, J. Fuel Cell Sci. Technol 12 (2015) 021008-021017. 
[9] A. Hauch, S. D. Ebbesen, S. H. Jensen, M. Mogensen, Solid oxide electrolysis cells: Microstructure and degradation of the Ni/Yttria-stabilized Zirconia electrode, J. Electrochem. Soc. 155 (2008) B1184-B1193.

[10] K. Eguchi, T. Hatagishi, H. Arai, Power generation and steam electrolysis characteristics of an electrochemical cell with a zirconia- or ceria-based electrolyte, Solid State Ionics 86-88 (1996) 1245-1249.

[11] T. Ishihara, T. Kanno, Steam electrolysis using $\mathrm{LaGaO}_{3}$ based perovskite electrolyte for recovery of unused heat energy, ISIJ Int. 50 (2010) 1291-1295.

[12] C. H. Wendel, P. Kazempoor, R. J. Braun, A thermodynamic approach for selecting operating conditions in the design of reversible solid oxide cell energy systems, J. Power Sources, 301 (2016) 93-104.

[13] C. H. Wendel, P. Kazempoor, R. J. Braun, Novel electrical energy storage system based on reversible solid oxide cells: System design and operating conditions, J. Power Sources, 276 (2015) 133-144.

[14] S.H. Jensen, X. Sun, S.D. Ebbesen, R. Knibbe, M. Mogensen, Hydrogen and synthetic fuel production using pressurized solid oxide electrolysis cells, Int. J. Hydrog. Energy 35 (2010) 9544-9549.

[15] T. Suzuki, T. Yamaguchi, K. Hamamoto, Y. Fujishiro, M. Awano, N. Sammes, A functional layer for direct use of hydrocarbon fuel in low temperature solid-oxide fuel cells, Energy Environ. Sci. 4 (2011) 940-943.

[16] Z. Zhan, D. Han, T. Wu, X. Ye, S. Wang, T. Wen, S. Cho, S. A. Barnett, A solid oxide cell yielding high power density below $600{ }^{\circ} \mathrm{C}$, RSC Adv. 2 (2012) 4075-4078.

[17] C. Graves, S. D. Ebbesen, M. Mogensen, Co-electrolysis of $\mathrm{CO}_{2}$ and $\mathrm{H}_{2} \mathrm{O}$ in solid oxide cells: Performance and durability, Solid State Ionics, 192 (2011) 398-403. 
[18] S.H. Jensen, C. Graves, M. Mogensen, C. Wendel, R. Braun, G. Hughes, Z. Gao, S.A. Barnett, Large-scale electricity storage utilizing reversible solid oxide cells combined with underground storage of $\mathrm{CO}_{2}$ and $\mathrm{CH}_{4}$, Energy \& Environ. Sci. 8 (2015) 2471-2479.

[19] D.M. Bierschenk, J.R. Wilson, S.A. Barnett, High efficiency electrical energy storage using a methane-oxygen solid oxide cell, Energy \& Environ. Sci. 4 (2011) 944-951.

[20] C.H. Wendel, Z. Gao, S.A. Barnett, R.J. Braun, Modeling and experimental performance of an intermediate temperature reversible solid oxide cell for high-efficiency, distributed-scale electrical energy storage, J. Power Sources 283 (2015) 329-342.

[21] W.L. Becker, R.J. Braun, M. Penev, M. Melaina, Production of Fischer-Tropsch liquid fuels from high temperature solid oxide co-electrolysis units, Energy 47 (2012) 99-115.

[22] X. Sun, M. Chen, S.H. Jensen, S.D. Ebbesen, C. Graves, M. Mogensen, Thermodynamic analysis of synthetic hydrocarbon fuel production in pressurized solid oxide electrolysis cells, Int. J. Hydrogen Energy 37 (2012) $17101-17110$

[23] J.E. O'Brien, M.G. McKellar, C.M. Stoots, J.S. Herring, G.L. Hawkes, Parametric study of large-scale production of syngas via high-temperature co-electrolysis, Int. J. Hydrogen Energy 34 (2009) 4216-4226.

[24] C. Graves, S.D. Ebbesen, M. Mogensen, K.S. Lackner, Sustainable hydrocarbon fuels by recycling $\mathrm{CO}_{2}$ and $\mathrm{H}_{2} \mathrm{O}$ with renewable or nuclear energy, Renew. Sustain. Energy, Rev. 15 (2011) 1-23.

[25] N. Xu, X. Li, X. Zhao, J. B. Goodenough, K. Huang, A novel solid oxide redox flow battery for grid energy storage, Energy Environ. Sci. 4 (2011) $4942-4946$ 
[26] X. Zhao, N. Xu, X. Li, Y. Gong, K. Huang, Long term stability study of a solid oxide metal-air battery, ECS Trans. 45 (2013) 113-121.

[27] X. Zhao, Y. Gong, X. Li, N. Xu, K. Huang, Cyclic durability of a solid oxide Fe-air redox battery operated at $650^{\circ} \mathrm{C}$, J. Electrochem. Soc. 160 (2013) A1716-A1719.

[28] A. Leonide, W. Drenckhahn, H. Greiner, Long term operation of rechargeable high temperature solid oxide batteries, Electrochem. Soc. 161 (2014) A1297-A1301.

[29] H. Ohmori, S. Uratani, H. Iwai, Numerical simulation of gas diffusion effects on charge/discharge characteristics of a solid oxide redox flow battery, J. Power Sources 208 (2012) 383-390.

[30] H. Ohmori, H. Iwai, 2-D simulation of heat and mass transfer effects on charge/discharge characteristics of a solid oxide redox flow battery, ECS Trans. 57 (2013) 233-242.

[31] H. Ohmori, H. Iwai, Simulation of solid oxide iron-air battery: Effects of heat and mass transfer on charge/discharge characteristics, J. Power Sources 286 (2015) 264-275.

[32] M. Guo, X. Zhao, R. E. White, K. Huang, A multi-physics model for solid oxide iron-air redox flow battery: Simulation of discharge behavior at high current density, J. Electrochem. Soc. 160 (2013) A2085-A2092.

[33] X. Jin, X. Zhao, R. E. White, K. Huang, Heat balance in a planar solid oxide iron-air redox battery: A computational analysis, J. Electrochem. Soc. 162 (2015) F821-F833.

[34] S. Wongchanapai, H. Iwai, M. Saito, H. Yoshida, Performance evaluation of an integrated small-scale SOFC-biomass gasification power generation system, J. Power Sources 216 (2012) 314-322.

[35] H. Iwai, H. Ohmori, K. Itakura, M. Saito, H. Yoshida, Numerical prediction of 
system efficiency of solid oxide redox flow battery during charge/discharge process, ECS Trans. 57 (2013) 2661-2670.

[36] K. Otsuka, C. Yamada, T. Kaburagi, S. Takenaka, Hydrogen storage and production by redox of iron oxide for polymer electrolyte fuel cell vehicles, Int. J. Hydrogen Energy 28 (2003) 335-342.

[37] E. Lorente, J. A. Pena, J. Herguido, Kinetic study of the redox process for separating and storing hydrogen: Oxidation stage and ageing of solid, Int. J. Hydrogen Energy 33 (2008) 615-626.

[38] K. Otsuka, T. Kaburagi, C. Yamada, S. Takenaka, Chemical storage of hydrogen by modified iron oxides, J. Power Sources 122 (2003) 111-121.

[39] H. Uechi, S. Kimijima, N. Kasagi, Cycle analysis of gas turbine-fuel cell cycle hybrid micro generation system, J. Engineering for Gas Turbines and Power, 126 (2004) 755-762.

[40] X. Jin, X. Zhao, J. Tong, F. Yasmeen, R. E. White, K. Huang, Energy efficiency of an intermediate-temperature solid oxide iron-air redox battery, J. Energy Storage 3 (2015) 1-9.

[41] T. Suzuki, Z. Hasan, Y. Funahashi, T. Yamaguchi, Y. Fujishiro, M. Awano, Impact of anode microstructure on solid oxide fuel cells, Science 325 (2009) 852-855. 


\section{Tables}

Table 1 Base operating conditions

\begin{tabular}{|c|c|c|c|}
\hline \multirow[t]{7}{*}{ System } & \multirow[t]{2}{*}{ Process time } & Charge, $t_{C}$ & $10 \mathrm{~h}$ \\
\hline & & Discharge, $t_{D}$ & $5 \mathrm{~h}$ \\
\hline & \multirow[t]{2}{*}{ Average current density } & Charge, $i_{C}$ & $50 \mathrm{~mA} / \mathrm{cm}^{2}$ \\
\hline & & Discharge, $i_{D}$ & $100 \mathrm{~mA} / \mathrm{cm}^{2}$ \\
\hline & \multirow[t]{2}{*}{ Temperature } & SOEC & $600^{\circ} \mathrm{C}$ \\
\hline & & Fe box & $600{ }^{\circ} \mathrm{C}$ \\
\hline & \multicolumn{2}{|l|}{ Electric capacity } & $5 \mathrm{kWh}$ \\
\hline \multirow[t]{5}{*}{ SOEC } & \multicolumn{2}{|c|}{ Output power output at discharge mode } & 1-kW-class \\
\hline & \multirow[t]{2}{*}{ Area-specific resistances [41] } & Ohmic, $A S R_{o h m}$ & $0.10 \Omega \mathrm{cm}^{2}$ \\
\hline & & Activation, ASRact & $0.25 \Omega \mathrm{cm}^{2}$ \\
\hline & \multicolumn{2}{|l|}{ Fuel utilization factor } & 0.5 \\
\hline & \multicolumn{2}{|l|}{ Air utilization factor } & 0.3 \\
\hline \multirow[t]{2}{*}{ Gas } & \multicolumn{2}{|c|}{ Fuel: Equilibrium state at $600^{\circ} \mathrm{C}$ at Fe box outlet } & $\begin{array}{l}\mathrm{H}_{2}: \mathrm{H}_{2} \mathrm{O}= \\
0.75: 0.25\end{array}$ \\
\hline & \multicolumn{2}{|c|}{ Air: Dry air at $25^{\circ} \mathrm{C}$ at air blower inlet } & $\begin{array}{l}\mathrm{N}_{2}: \mathrm{O}_{2}= \\
0.79: 0.21\end{array}$ \\
\hline \multirow[t]{2}{*}{ Other } & \multicolumn{2}{|c|}{ Maximum allowable temperature of fuel-blower } & $150{ }^{\circ} \mathrm{C}$ \\
\hline & \multicolumn{2}{|l|}{ Heat exchangers Effectiveness } & 0.85 \\
\hline
\end{tabular}


Table 2 Gas temperatures at various points in the system under the base operating conditions

Charge:

\begin{tabular}{rlrrr}
\hline \hline & Path & Gas & In & \multicolumn{1}{c}{ Out } \\
\hline \multirow{2}{*}{ HEX1 } & Hot side & Fuel & $600{ }^{\circ} \mathrm{C}$ & $136{ }^{\circ} \mathrm{C}$ \\
\cline { 2 - 5 } & Cold side & Fuel & $49{ }^{\circ} \mathrm{C}$ & $517^{\circ} \mathrm{C}$ \\
\hline \multirow{2}{*}{ HEX2 } & Hot side & Fuel & $136{ }^{\circ} \mathrm{C}$ & $49{ }^{\circ} \mathrm{C}$ \\
\cline { 2 - 5 } & Cold side & Air & $25{ }^{\circ} \mathrm{C}$ & $119{ }^{\circ} \mathrm{C}$ \\
\hline \multirow{2}{*}{ HEX3 } & Hot side & Air & $600^{\circ} \mathrm{C}$ & $223^{\circ} \mathrm{C}$ \\
\cline { 2 - 5 } & Cold side & Air & $119^{\circ} \mathrm{C}$ & $528^{\circ} \mathrm{C}$ \\
\hline \multirow{2}{*}{ Fuel Blower } & & Fuel & $49{ }^{\circ} \mathrm{C}$ & - \\
\hline
\end{tabular}

Discharge:

\begin{tabular}{rlrrr}
\hline \hline & Path & Gas & In & \multicolumn{1}{c}{ Out } \\
\hline \multirow{2}{*}{ HEX1 } & Hot side & Fuel & $600{ }^{\circ} \mathrm{C}$ & $89{ }^{\circ} \mathrm{C}$ \\
\cline { 2 - 5 } & Cold side & Fuel & $26{ }^{\circ} \mathrm{C}$ & $540{ }^{\circ} \mathrm{C}$ \\
\hline \multirow{2}{*}{ HEX2 } & Hot side & Fuel & $89{ }^{\circ} \mathrm{C}$ & $26{ }^{\circ} \mathrm{C}$ \\
\cline { 2 - 5 } & Cold side & Air & $25{ }^{\circ} \mathrm{C}$ & $48{ }^{\circ} \mathrm{C}$ \\
\hline \multirow{2}{*}{ HEX3 } & Hot side & Air & $600{ }^{\circ} \mathrm{C}$ & $202^{\circ} \mathrm{C}$ \\
\cline { 2 - 5 } & Cold side & Air & $48{ }^{\circ} \mathrm{C}$ & $432{ }^{\circ} \mathrm{C}$ \\
\hline \multirow{2}{*}{ Fuel Blower } & & Fuel & $26{ }^{\circ} \mathrm{C}$ & - \\
\hline
\end{tabular}




\section{Figure captions}

Figure 1. System configuration and main heat input/output (a) A simple system configuration, (b) A system configuration with thermal energy recirculation by heat exchangers.

Figure 2. Sankey diagram of SOIAB (a) in which the thermal energy required to preheat the gases is considered and (b) with three heat exchangers.

Figure 3. Effects of heat exchanger effectiveness on the system round-trip efficiency. Figure 4. Effects of the fuel and air utilization factors on the system (a) Round-trip efficiency, (b) Operating window for the efficient and uniform operation of the system.

Figure 5. Effects of the current density on the system round-trip efficiency. 


\section{Nomenclature}

ASR

E

F

$\Delta \mathrm{G}^{0}$

$\Delta_{\mathrm{r}} \mathrm{H}$

i

Q

$\mathrm{R}$

$\Delta S$

$\mathrm{t}$

$\mathrm{T}$

$\mathrm{P}$

$\mathrm{p}$

V

Greek symbols

$\eta$

$\eta_{\mathrm{C}}$ and $\eta_{\mathrm{D}}$

\section{Subscripts}

C

$\mathrm{D}$

ohm

act

j
Area-specific resistances of $\operatorname{SOEC}\left(\Omega \mathrm{cm}^{2}\right)$

Electromotive force of SOEC (V)

Faraday constant, $96485\left(\mathrm{C} \mathrm{mol}^{-1}\right)$

Change in standard Gibbs free energy $\left(\mathrm{J} \mathrm{mol}^{-1}\right)$

Enthalpy change of reaction $\left(\mathrm{J} \mathrm{mol}^{-1}\right)$

Average current density $\left(\mathrm{A} \mathrm{m}^{-2}\right)$

Heat input or output (J)

Gas constant, $8.314\left(\mathrm{~J} \mathrm{~mol}^{-1} \mathrm{~K}^{-1}\right)$

Entropy change $\left(\mathrm{J} \mathrm{mol}^{-1} \mathrm{~K}^{-1}\right)$

Process time in hour (h)

Temperature (K)

Electricity input or output (J)

Average partial pressure (Pa)

Terminal voltages (V)

System round-trip efficiency (-)

Potential losses (V)

Charge process

Discharge process

Ohmic loss

Activation overpotential loss

Species 
Meaning of symbols

SOIAB Solid oxide iron-air battery

SOEC Solid oxide electrochemical cell 
(a) A simple system configuration

(Charge)

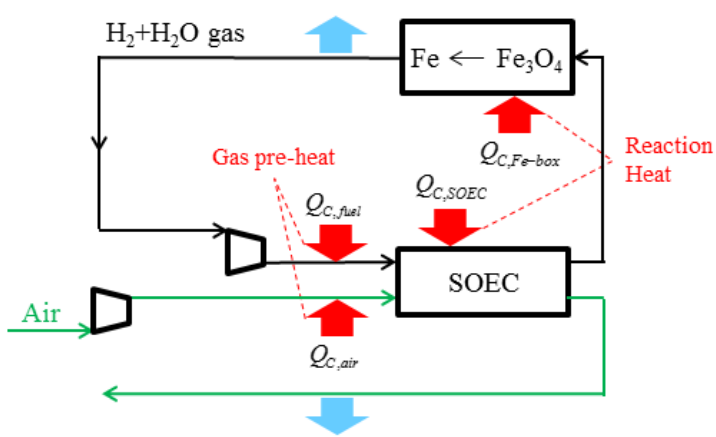

(Discharge)

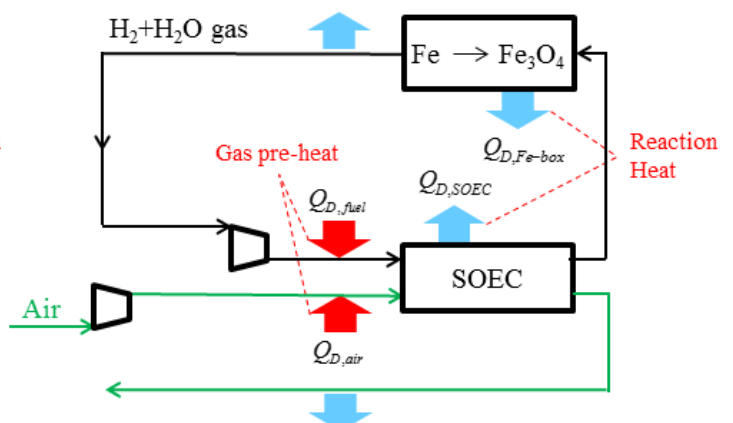

(b) A system configuration with thermal energy recirculation by heat exchangers (Charge)

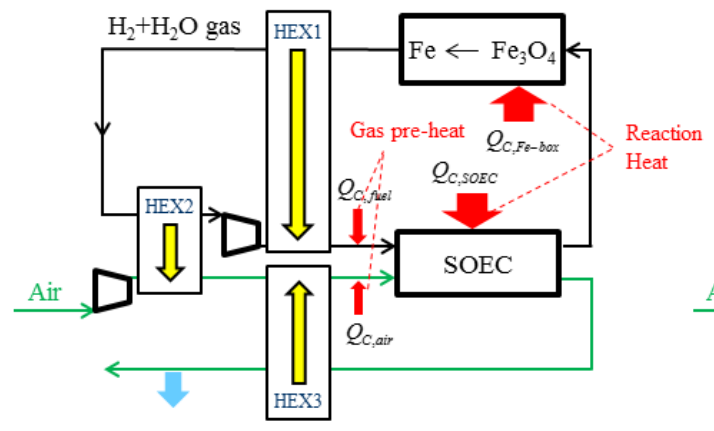

(Discharge)

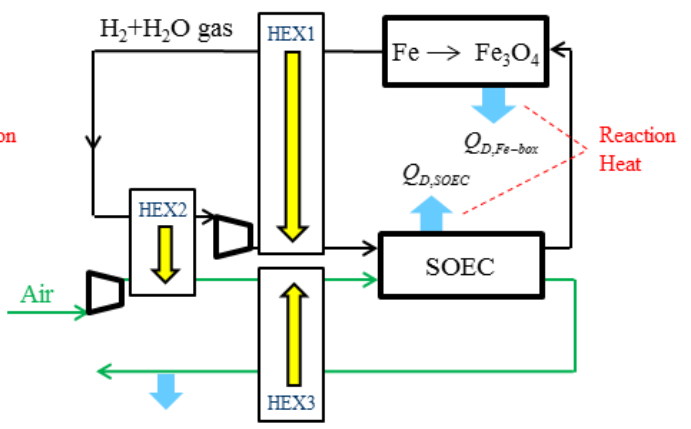

Heat input to the system

Figure 1. System configuration and main heat input/output (a) A simple system configuration, (b) A system configuration with thermal energy recirculation by heat exchangers. 


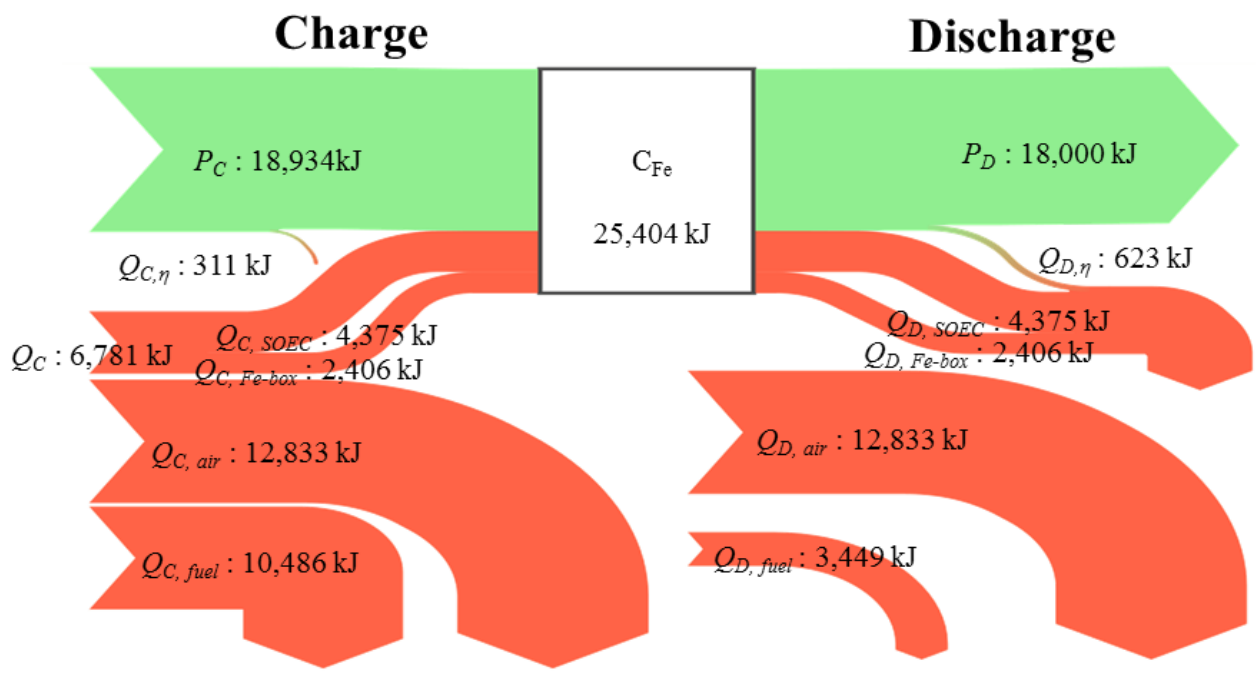

(a)

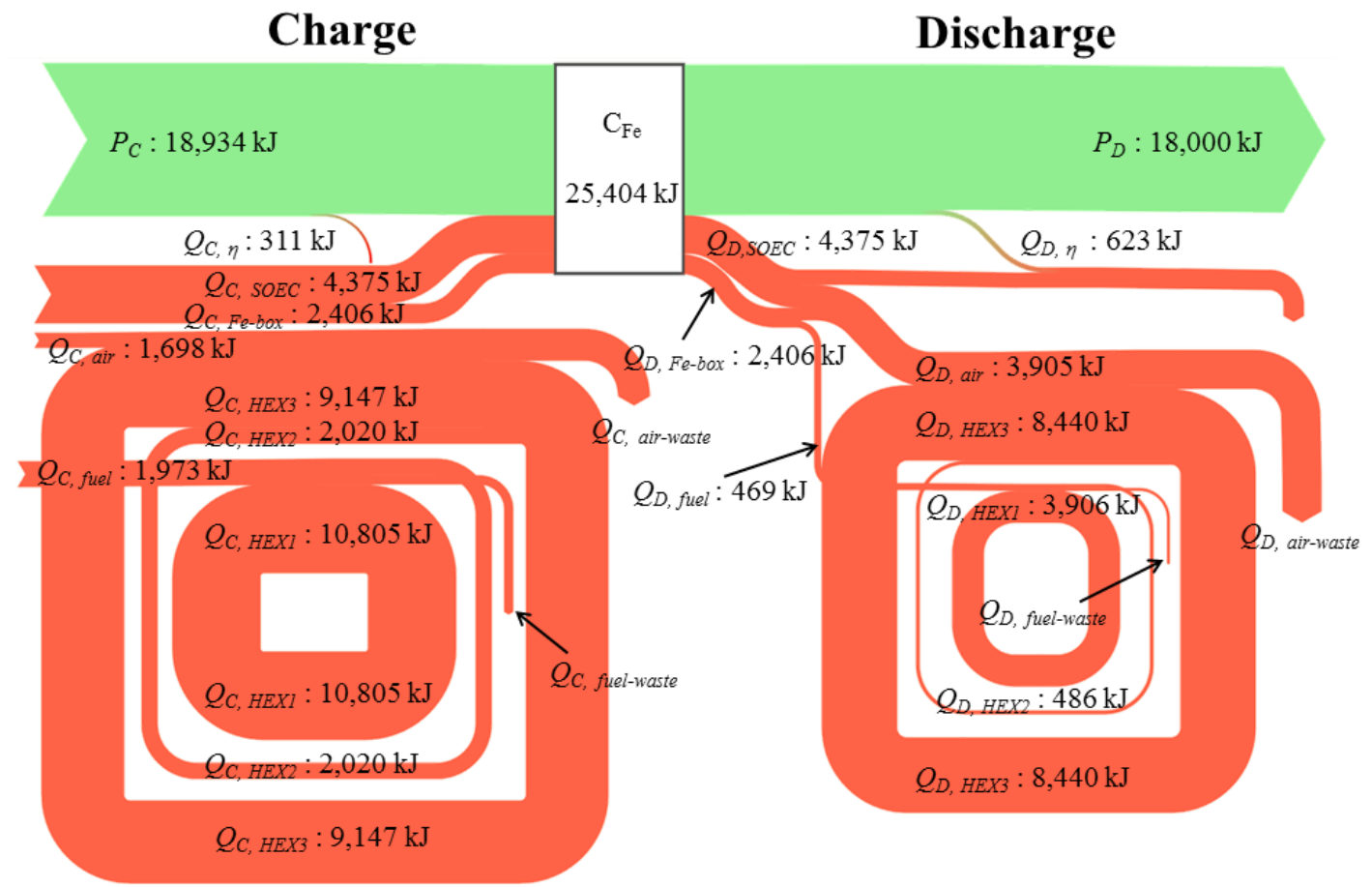

(b)

Figure 2. Sankey diagram of SOIAB (a) in which the thermal energy required to preheat the gases is considered and (b) with three heat exchangers. 


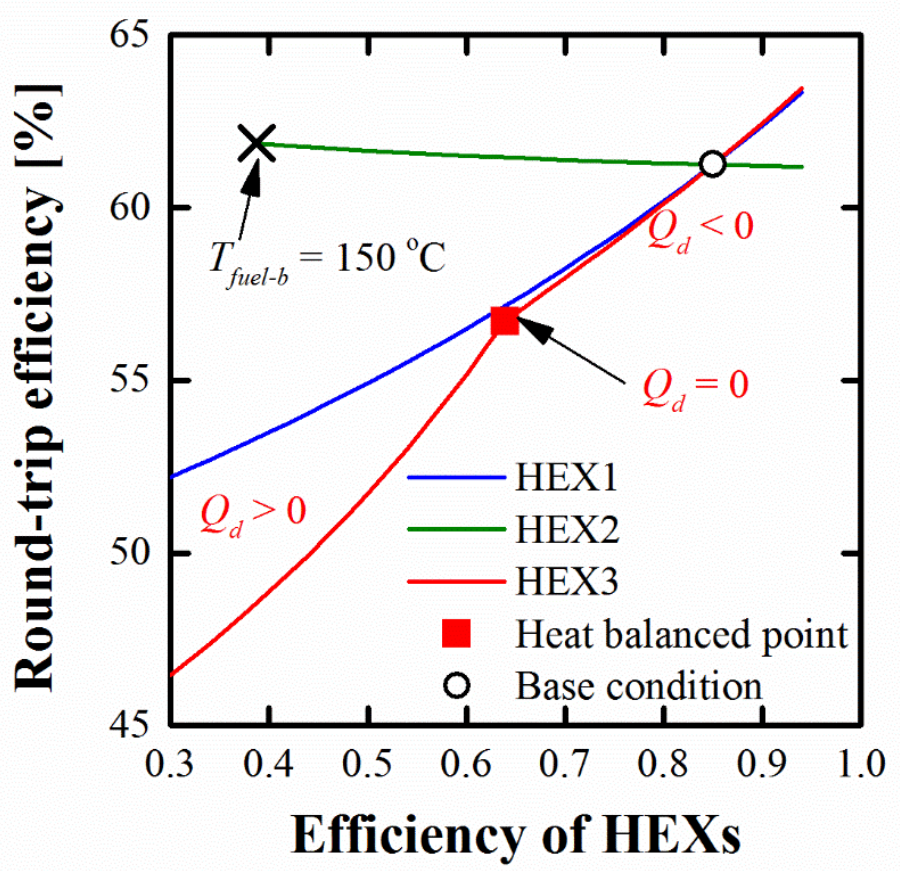

Figure 3. Effects of heat exchanger effectiveness on the system round-trip efficiency. 


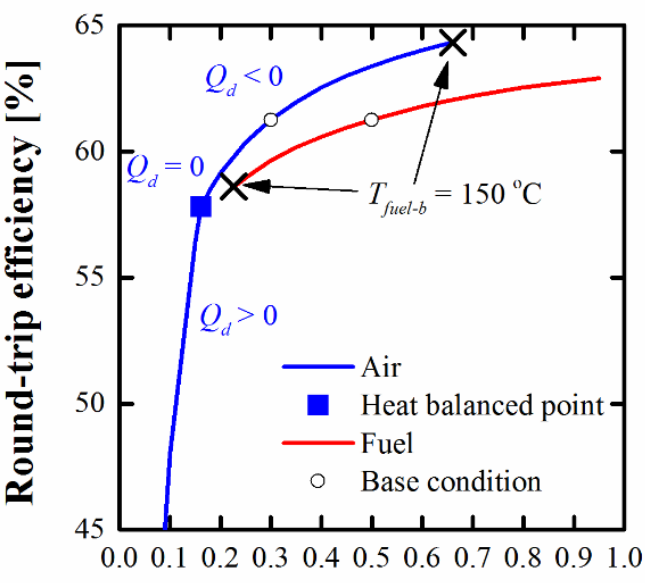

Gas utilization factors

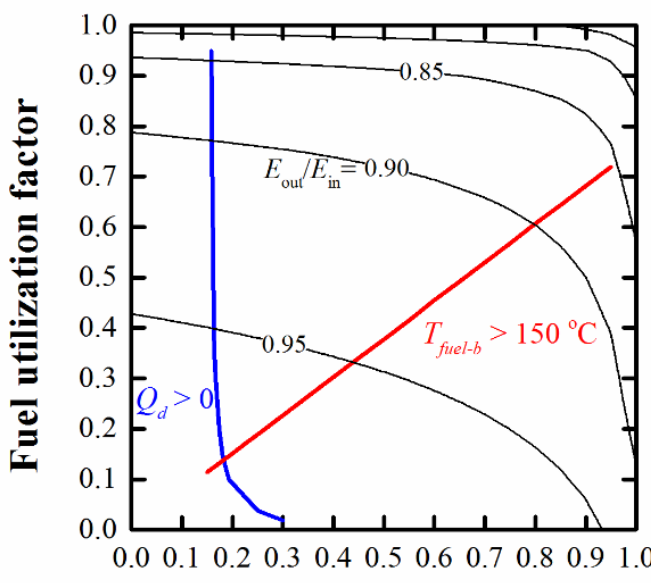

Air utilization factor

(b)

Figure 4. Effects of the fuel and air utilization factors on the system (a) Round-trip efficiency, (b) Operating window for the efficient and uniform operation of the system. 


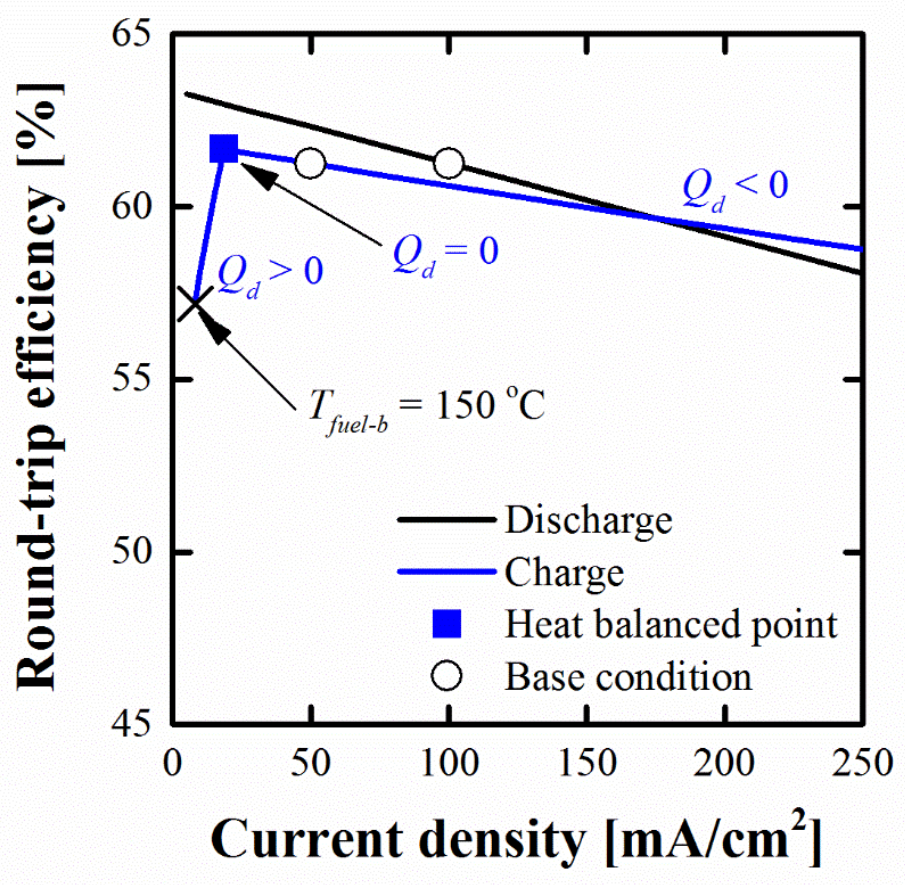

Figure 5. Effects of the current density on the system round-trip efficiency. 